\title{
RELAÇÕES CONJUGAIS DE PARCEIROS HIV SOROPOSITIVOS CONCORDANTES: UMA VISÃO MASCULINA ${ }^{1}$
}

\author{
Marco Antonio de Castro Figueiredo \\ Natália Maria Terenzi
}

\begin{abstract}
RESUMO. Tomando como ponto de partida a vulnerabilidade feminina à infecção por HIV e a conseqüente feminilização da epidemia de aids, este estudo buscou identificar algumas representações de relações conjugais tendo como referência homens que transmitiram o HIV à companheira. Entrevistas semi-estruturadas com dez homens HIV-soropositivos que contaminaram a parceira permitiram a identificação de conteúdos relacionados com algumas categorias temáticas: a) provedor masculino, que relega o trabalho da mulher à condição de um complemento no orçamento doméstico; b) dialética passivo-ativa, que contrapõe o caráter contemplativo dos papéis femininos à iniciativa, característica do masculino; c) naturalização da infidelidade masculina, com conteúdos sobre assimetria de gêneros relacionada à liberdade do homem nas questões sexuais; d) feminilização do cuidado, que destaca o caráter continente do feminino, naturalizado pelas atribuições domésticas da mulher. Estes resultados poderão oferecer subsídios importantes para a concepção de programas de orientação sobre relações conjugais e questões de gênero, dentro do contexto da feminilização do HIV/aids.
\end{abstract}

Palavras-chave: HIV/AIDS, relações conjugais, papéis de gênero.

\section{CONJUGAL RELATIONS OF HIV SERUM-POSITIVE CONCORDANT PARTNERS. A MASCULINE'S POINT OF VIEW}

\begin{abstract}
Since females are more vulnerable to HIV infection and since more women have been AIDS-infected, current study identifies representations of conjugal relationships with special reference to males who have transmitted HIV to their wives. Based on semi-structured interviews with 10 serum-positive males who transmitted the disease to their wives, the following thematic categories have been identified: a) male wage-earner who relegated partner's work as secondary income; b) active-passive dialectics which counterpoints the contemplative traits of female roles to an initiative-taking one, considered a male role; c) naturalization of male infidelity, with gender asymmetry linked to male sexual freedom; d) female prevalence in caretaking, which emphasizes women's continence traits, naturalized by domestic attributions to women. Results show that important items may be presented towards the development of programs for the orientation and resistance against gender subordination within the context of the women's vulnerability to HIV-Aids infection.
\end{abstract}

Key words: HIV-Aids, vulnerability, gender roles.

\section{RELACIONES CONYUGALES EN COMPAÑEROS VIH SEROPOSITIVOS CONCORDANTES. UNA VISIÓN MASCULINA}

\begin{abstract}
RESUMEN. Tomando como punto de partida la vulnerabilidad de la mujer a la infección por el VIH y la consiguiente feminización de la epidemia del SIDA, este estudio busca identificar algunas representaciones sobre las relaciones conyugales, teniendo como referencia hombres que transmitieron el VIH a la pareja. Entrevistas semi-estructuradas con diez hombres VIH seropositivos, posibilitaron la identificación de contenidos relacionados con algunas categorías temáticas: a) macho proveedor, que relega el trabajo femenino a la condición de suplemento en el presupuesto familiar, b) dialéctica pasivo/activo, que contrasta el carácter contemplativo de las funciones femeninas a la iniciativa, característica de los varones c) la naturalización de la infidelidad masculina, con contenido sobre la asimetría de géneros, relacionados con la libertad del hombre en cuestiones sexuales d) feminización de la atención, destacando el carácter continente del femenino, naturalizado pelas tareas domésticas de la mujer. Estos resultados podrán conceder informaciones importantes para el diseño de proyetos que miran a la orientación de relaciones conyugales y las cuestiones de género en el contexto de la feminización del VIH / SIDA.
\end{abstract}

Palabras-clave: VIH / SIDA, relaciones conyugales, papeles de género.

\footnotetext{
Apoio: CNPq.

* Professor Titular junto ao Departamento de Psicologia e Educação, da FFCLRP, Universidade de São Paulo-USP.

\# Mestre em Psicologia.
} 
No seu surgimento, em fins dos anos 70 , por se manifestar principalmente em homossexuais masculinos (Ayres, França Jr \& Calazans, 1997), a aids era concebida como uma afecção característica de um grupo de risco (Herek \& Glunt, 1988) determinando pré-concepções sobre pessoas que manifestavam os sintomas da doença (Clausson, 1989).

Posteriormente, levada pela expansão para além dos chamados grupos de risco (Castiel, 1996), a atribuição da infecção foi substituída pela noção de comportamento de risco (Bastos \& Szwarcwald, 2000; Schechter, 1993), que passou a ser considerado como um elemento de visibilidade e de enfoque estratégico dentro da epidemiologia da aids. A ênfase no comportamento, longe de eliminar as pré-concepções sobre a aids, foi um novo elemento de culpabilidade das pessoas pelo contágio por HIV (Ayres et al., 1997; Bastos, Boschi-Pinto, Telles \& Lima, 1993).

Ao longo das últimas décadas a epidemia de aids passou a atingir outros segmentos mais vulneráveis, acometendo as camadas mais pobres da sociedade (Farmer, Connors, Simmons, 1996; Parker \& Camargo $\mathrm{Jr}$, 2000). Alguns processos determinados pela exclusão social deram um novo contorno à epidemia, potencializada pela pauperização, feminilização e interiorização do contágio por HIV (Bastos \& Szwarcwald, 2000; Vermelho, Barbosa \& Nogueira, 1999).

O conceito de vulnerabilidade constitui, atualmente, um elemento importante para dar visibilidade às subpopulações e indivíduos mais sujeitos à contaminação por HIV, uma vez que permite identificar as condições às quais as pessoas estão expostas e que as tornam mais afetas ao HIV (Ayres, 2002; Vermelho et al., 1999).

Neste contexto de vulnerabilidade a mulher tem sido um elemento de destaque: a feminilização do contágio por HIV é um fenômeno que se reforça e se potencializa ao longo da epidemia de aids (Fernandes, Antonio, Bahamondes \& Cupertino, 2000; Franco \& Figueiredo, 2004; Mota, 1998).

$\mathrm{O}$ aumento da quantidade de mulheres contaminadas pelo vírus HIV, principalmente daquelas que adquiriram aids por meio de relações heterossexuais, deve-se à desigualdade de gênero, associada à pobreza e à subordinação dos papéis femininos em nossa sociedade (Saldanha, 1998). A vinculação da pobreza às questões de gênero representa uma dupla determinação da extrema vulnerabilidade da mulher à contaminação por HIV (Parker, 1997; Parker \& Camargo Jr, 2000). Para estes últimos, o Brasil reúne todos estes elementos, potencializando a vulnerabilidade feminina associada à Aids: "A falta de poder das mulheres sujeitas simultaneamente à opressão de gênero repete-se tanto nas grandes cidades quanto nas áreas rurais do país; o encolhimento do mercado formal de trabalho e a desintegração social produzida pelo crime organizado e o tráfico de drogas..." (p. 14).

Dentro desta perspectiva, alguns trabalhos sobre vulnerabilidade feminina foram desenvolvidos por uma equipe de pesquisadores, dentro do Programa de Atendimento Psicossocial à aids do Departamento de Psicologia e Educação da Faculdade de Filosofia, Ciências e Letras de Ribeirão Preto, USP, considerando mulheres com HIV usuárias de drogas injetáveis (Franco \& Figueiredo, 2004); trabalhadoras à margem do mercado de trabalho (Ferreira \& Figueiredo, 2006), cuidadoras domésticas de crianças soropositivas ao HIV (Bossa \& Figueiredo, 2002) e mulheres contaminadas pelos maridos em relações conjugais estáveis (Fioroni \& Figueiredo, 2004; Saldanha \& Figueiredo, 2004). Em todos estes trabalhos foram identificados processos de subordinação da mulher aos papéis e relações de gênero.

O presente trabalho complementa outros estudos, já que a infecção de grande parte das mulheres decorreu da determinação dos papéis de gênero nas relações conjugais. Alguns autores (Heilborn, 1994; Scott, 1989) concebem as relações de gênero como determinantes das experiências sexuais das pessoas, suas cargas eróticas e suas contradições:

\begin{abstract}
Ao nos referirmos a gênero, apontamos para um debate que diz respeito à concepção do que é ser masculino ou feminino na sociedade, aspecto que interpela a experiência sexual dos sujeitos, modela o mundo dos significados eróticos ... Nesse sentido, o gênero é um aspecto maleável que torna possível que se reconheçam não apenas às semelhanças e igualdades existentes entre os sujeitos sociais, mas os padrões de coerência cultural que existem na razão mesmo da diferença que os separa ... (p. 5).
\end{abstract}

Vimos que um dos elementos principais da vulnerabilidade feminina à aids se refere aos papéis de gênero e ao contágio pelos parceiros. $\mathrm{O}$ presente trabalho é uma tentativa de verificar o outro lado da moeda, ou seja, as representações masculinas sobre ter transmitido o HIV para sua parceira.

Considerando estas questões, este trabalho visa contrapor à perspectiva comumente feminina que tem inspirado a maioria dos estudos referentes à transmissão heterossexual do HIV, o ponto de vista do 
parceiro, buscando uma síntese entre representações femininas e masculinas quanto à relação conjugal e ao contágio.

Estudos sobre o universo feminino e sua vulnerabilidade ao contágio por HIV têm sido amplamente desenvolvidos, observando-se uma grande dificuldade da mulher para se proteger, dada a sua subordinação aos papéis masculinos, na relação conjugal. Este estudo constitui uma busca por conteúdos afetivos e cognitivos relacionados aos papéis masculinos que tornam a mulher vulnerável à contaminação pelo HIV. Representa, sob a perspectiva da contraposição com as representações femininas sobre o convívio doméstico no contexto do contágio por HIV, a possibilidade de uma síntese, com desdobramentos interessantes para a atuação profissional nestas questões.

\section{OBJETIVOS}

O presente estudo teve como objetivo identificar, nos elementos masculinos do casal, conteúdos relacionados ao convívio doméstico no contexto da transmissão do HIV à parceira e suas consequiências para a relação. Tais conteúdos poderão ser fundamentais na busca por elementos subsidiários à concepção/administração de programas voltados às relações conjugais no contexto do contágio por HIV.

\section{MÉTODO}

\section{Participantes}

Foram estudados 10 homens soropositivos ao HIV, que sabidamente transmitiram o vírus para a parceira, atendidos na Unidade Especial de Terapia de Doenças Infecciosas- UETDI do Hospital das Clínicas da Faculdade de Medicina de Ribeirão Preto, USP. Para viabilizar sua participação, o projeto foi submetido à Comissão de Normas Éticas desse hospital, e só após o consentimento a coleta de dados foi iniciada.

Os participantes foram contatados com base na busca em prontuários e indicações de assistentes sociais e psicólogos pertencentes à Unidade. Após um primeiro contato, para explicar o objetivo da pesquisa, a entrevista era agendada, podendo o participante escolher para sua realização: a) o dia de retorno à consulta médica; b) a própria casa do participante, e c) dia que não o de consulta, na Unidade.

As entrevistas foram feitas sempre em locais reservados e protegidos de interferências que comprometessem o sigilo, e somente quando as pessoas se encontrassem em condições físicas e emocionais para participar da pesquisa. A participação foi absolutamente voluntária, sendo assinados termos de consentimento informado, no sentido de garantir os preceitos da ética em pesquisa com seres humanos.

\section{Procedimentos}

Foram feitas entrevistas semi-estruturadas focalizando as relações conjugais, dentro do contexto de soroconcordância positiva de parceiros ao HIV, definidas como vivências rotineiras do dia-a-dia do casal, referentes não apenas às relações afetivas, mas também à divisão do trabalho doméstico e outras questões de papéis dentro da família.

As entrevistas foram conduzidas segundo o procedimento não-diretivo proposto por Ribeiro (1996), que compreende três etapas sucessivas e interdependentes, visando a uma participação ativa e conduzida dentro do referencial da pessoa entrevistada, como se segue:

1. Evocação: eram dados à pessoa entrevistada aproximadamente trê minutos para que pensasse sobre um dos aspectos abordados pela entrevista. Esta etapa permitiu retirar conteúdos situados no próprio referencial dos sujeitos, minimizando a indução.

2. Enunciação: pedia-se à pessoa que enunciasse, verbalmente, os conteúdos que julgasse mais importantes. $\mathrm{O}$ entrevistador anotava ipsis litteris o que havia sido dito pela pessoa entrevistada. Tal procedimento visava manter a integridade do relato, feito com as expressões e palavras do próprio repertório do entrevistado.

3. Averiguação: partindo dos enunciados sobre os conteúdos evocados, a entrevista era complementada verificando-se cada uma das enunciações em particular. Esta etapa, considerada a entrevista propriamente dita, era gravada em fita cassete para transcrição e posterior análise de conteúdos. Esta última etapa permitiu, com base no relato enunciado, dirigir a entrevista para os objetivos e metas da pesquisa.

\section{Análise de conteúdo e tratamento dos dados}

A análise das transcrições das entrevistas foi processada com base na inclusão dos diversos trechos, selecionados em categorias temáticas a posteriori, considerando cada depoimento em particular e realizando uma síntese, e ao final, tomando individualmente tais categorias. Este procedimento foi 
realizado ao longo de algumas etapas, a seguir colocadas e descritas:

a) Leitura inicial: nessa etapa foram identificados alguns pontos preliminares ligados ao tema tratado, realizando-se anotações sobre aspectos relacionados aos conteúdos evocados.

b) Marcação: foi feita uma seleção de trechos das entrevistas que correspondiam aos objetivos do trabalho, além de outros conteúdos considerados importantes, que poderiam ser também incluídos.

c) Corte: os trechos selecionados foram, então, retirados do texto e dispostos em protocolos especialmente construídos para a análise de conteúdo.

d) Junção: foi feito um agrupamento por entrevista, ou seja, todos os depoimentos de uma mesma pessoa foram reunidos em um protocolo particular.

e) Notação: foram feitas observações marginais para cada trecho selecionado e todos eles foram agrupados em categorias temáticas, com vista a referenciá-los na literatura e no contexto da entrevista.

f) Segunda junção: as observações marginais foram discutidas para fazer uma segunda junção agrupando os resultados de todas as pessoas em uma mesma categoria.

g) Redação final: finalmente, com base nos dados agrupados por categorias, foi realizada a redação final do material.

\section{RESULTADOS E DISCUSSÃO}

Considerando-se os conteúdos identificados nos depoimentos dos participantes entrevistados, para relações conjugais foram definidas quatro categorias temáticas, apresentadas a seguir.

1. Provedor masculino: para esta categoria temática, os conteúdos evocados em diversos depoimentos se caracterizam pelo "toque" dos papéis de gênero, nos quais, na maioria das vezes, o trabalho feminino era quase proibido e sua contribuição considerada complemento dentro do orçamento doméstico. Inscritos nesta categoria, estão os conteúdos referentes às crenças naturalizadas sobre o caráter provedor do homem, a quem cabia o sustento do lar.

2. Dialética passivo/ativo: nesta categoria temática é bastante saliente o caráter contemplativo do papel feminino, em contraponto à iniciativa, característica do homem, concentrando conteúdos relacionados a crenças a respeito da passividade da mulher, em contrapartida à atividade masculina no enfrentamento diário do convívio doméstico.

3. Naturalização da infidelidade masculina: esta categoria temática concentra conteúdos característicos da assimetria de gêneros ligada à liberdade e autodeterminação relativa às questões sexuais, papéis que determinam crenças sobre a dominação masculina nas relações de gênero, o que faculta ao homem a possibilidade de múltiplas parceiras.

4. Feminilização do cuidado: finalmente, em uma quarta categoria temática se destacaram significados relativos ao caráter de continência das mulheres, naturalizado pelas atribuições domésticas dos papéis de gênero, em contraponto ao atual processo de proletarização da mulher, levando, em alguns depoimentos, à identificação de dupla jornada de trabalho, subsidiária à manutenção do orçamento doméstico. Prevaleceram nesta categoria conteúdos sobre a concepção do feminino como continente, o que atribui à mulher funções de cuidadora.

Considerando a análise de conteúdo dos enunciados das entrevistas referentes às relações conjugais, as categorias temáticas identificadas estão assentadas em formas naturalizadas de papéis de gênero, com destaque às funções do homem como provedor da mulher como responsável pelos cuidados domésticos. Além disso, a naturalização se estende ao próprio ato sexual em si, conferindo uma essência de passividade à mulher e atividade ao homem. Da mesma forma, o mito da dominação masculina lhe confere, na relação, a "parte do leão", seja na "corte", seja nos recursos do lar.

Esses dados corroboram uma série de elementos da vulnerabilidade feminina. Esta vulnerabilidade se consolida na posição de subordinação da mulher, a quem o papel que cabe é o de cuidar. Segundo Vaitsman (1994), a família moderna é patriarcal, e, na prática, nela se constitui uma divisão sexual do trabalho, cujo objetivo é a criação dos filhos. Esta divisão é fundada numa hierarquia entre os sexos que coloca a mulher numa posição subordinada. Também, para essa autora, nas relações sexuais a mulher ocupa uma posição de passividade e, quando tenta quebrar esta postura e se equiparar ao homem, não é bem vista:

De modo geral, o sexo pelo sexo é permitido, e até mesmo estimulado para os homens, sendo associado à masculinidade, virilidade, poder. Para a mulher, no entanto, o sexo, na maioria 
das vezes, ainda é tabu. Se ela busca prazer no sexo, sem amor ou sem vínculo, é considerada promíscua, volúvel (Vaitsman,1994, p. 49).

Estas questões podem ser identificadas nos enunciados das nossas entrevistas. $\mathrm{O}$ participante 01 , ao se referir ao trabalho da companheira fora do lar, mesmo invocando a vontade da mulher, faz prevalecer o exercício da dominação masculina impedindo-a: "Ela sempre teve vontade de trabalhar, mas eu nunca quis..." (part. 01).

Podem-se observar nesta enunciação alguns elementos importantes do impedimento no domínio de gênero, os quais, no entanto, têm no seu cerne a manutenção do papel de provedor.

Em grande parte dos enunciados dos homens entrevistados percebe-se claramente o papel que eles consideram típico da mulher dentro das relações conjugais, atribuindo às companheiras as funções de cuidado, tanto deles próprios quanto do lar e dos filhos.

\footnotetext{
"Porque eu quero que ela fica cuidando das meninas, entendeu?" (part. 01).

“... que vai ser bom pra mim, pode ser bom pra mim assim, pra eu me entender com essa pessoa, a gente se entender muito bem e ela cuidar de mim e dele (filho), obviamente" (part. 02).

“... também agora nem dá tempo de sair porque ela trabalha, chega em casa e cuida de mim, né?" (part. 04).
}

"Ela trabalha de empregada, mas agora não pode mais porque tem que me trazer aqui" (part. 05).

“A minha relação com J. é totalmente legal, eu conheci ela na hora que eu estava precisando de alguém pra cuidar de mim, é tá muito legal" (part.06)

"Quando morava comigo, ficava cuidando dos filhos, da casa" (part. 07).

"Eu trabalhava e ela não, cuidava da casa, eu preferia assim" (part. 08).

"Não, ela ficava tomando conta da casa..." (part. 10).

Foram também observados enunciados sobre introjeção de responsabilidade, em que muitas vezes o elemento masculino mostra culpabilidade por não estar cumprindo seu papel como provedor. Alguns enunciados demonstram, claramente, as dificuldades dos homens para enfrentar a impossibilidade de "honrar" uma responsabilidade que seria dele:
"Eu tinha muita opressão pela mãe dela. Ela ficava falando pra ela que eu não tava trabalhando, (...) que eu não tinha futuro pra ela... (...) Os dois trabalhavam, ela trabalhava numa empresa de costura, mas era eu quem sustentava a casa..." (part. 03).

"Eu era carpinteiro, agora estou afastado... Não posso mais dar dinheiro em casa, mas tem que levar a vida" (part. 04).

"Aposentei. Eu trabalhava na fazenda, na roça. Sustentava a casa, agora tá difícil com o dinheiro que tem..." (part. 05).

"Eu trabalhava numa firma, mas depois que eu fiquei doente pedi pra me aposentar. Agora faço alguns bicos como encanador, pra ver se dá mais um dinheirinho em casa..." (part. 10).

Alguns enunciados ilustram a relação de dominação dos homens sobre a vontade da mulher. Muitas vezes eles se sentem no direito de administrar comportamentos e impor necessidades às suas parceiras, mesmo contra a vontade destas, subjugandoas numa relação de poder em que o "mandante" é o homem:

"Levo as meninas pra ir tomar lanche, no Mac Donald's na Divertilândia, no shopping. Mando a P. levar elas, vai no cinema" (part. 01).

"E eu peguei e pus ela no carro, fui lá e falei: 'pega tuas coisas e vamo embora', e eu peguei e trouxe ela pra cá” (part. 01).

“...Várias vezes, quando acontecia um bateboca, era porque ela era muito vaidosa, gastava muito dinheiro, entendeu?" (part. 03).

"E ela disse: 'vou falar, se quiser me mandar embora, manda'. Eu disse: 'Não tem que parar de trabalhar, vai ficar o dia todo sem fazer nada? Tem que trabalhar'” (part. 04).

Encontramos nos depoimentos alguns elementos que caracterizam o lugar ocupado por cada um na relação: à mulher pertence a esfera privada e ao homem a esfera pública, cabendo-lhe o controle dos locais em que se encontre a sua mulher:

"Eu trabalhava à noite, e às vezes eu saía, ia pras boates, ficava tomando umas cervejas com os amigos...mas eu não era assim... farrento, sabe? Me preocupava demais com ela, sempre procurava...em todo lugar que eu tava procurava falar pra ela onde eu tava, 
porque se precisasse de mim sabia, viu?" (part. 01).

"A gente se dava bem, algumas brigas por ciúmes... Eu gostava muito de sair com os amigos pra tomar uma cerveja... e às vezes chegava tarde, ela não gostava... teve vez que eu tava meio alto, sabe?" (part. 10).

Em contraponto à dominação masculina, a passividade da mulher, cuja liberdade é reprimida, naturaliza a assertividade do homem. Alguns depoimentos são bastante claros:

\footnotetext{
"Agora, ela não é muito de sair, ela fica lá comigo" (part. 04).

"Não, ela tinha paciência. Ela não falou nada pra mim, não brigou, nem discutiu" (part. 06).
}

Outro destaque nos enunciados se refere à naturalização da infidelidade masculina, vista como um direito de provedor. Para estes, é natural que de vez em quando haja uma traição, o que pode ser visto nos seguintes depoimentos:

"Mas, às vezes, eu dava algumas escapadinhas com os colegas, mas nem sempre eu ia atrás de mulher” (part. 01).

“...ela falou que queria morar junto, e aí eu falei: 'Olha o negócio é o seguinte, eu vou te explicar, pra depois amanhã não ter problema, né? Eu sou um cara bagunceiro, não de briga e de bebida. Eu gosto é de ficar sempre numa arruaça...' Aí ela falou: 'Não, não tem problema'. Eu falei: 'Não tem agora, depois pode ter algum problema no meio...' Depois ela achava que eu era culpado, aí eu peguei e falei: 'Ó, o negócio é o seguinte: eu não te avisei que era bagunceiro?’” (part. 05).

"Claro, ficava com outras... ela não saía de casa, ela era totalmente..., quer dizer esse era o conceito que eu tinha sobre ela, ela não vou citar nomes..., ela era assim na época, boboca" (part. 09).

Em contraponto à naturalização da infidelidade masculina, quando ocorre o oposto a mulher é vista como invasora de um espaço que não lhe pertence, o que pode ser notado na fala do participante 09 :

“... você namora quem você quiser e eu também... aí eu liberei geral. Você quer ser homem? (...) Foi quando eu voltei pra cá, a gente tentou ficar junto, mas ela aprontou de novo, me traiu de novo, aí meti a mão na cara dela...".
O ciúme aparece como elemento da personalidade feminina; afinal a esfera pública é de domínio masculino e a única forma de controle feminino são as brigas:

"Eu sofri muito, porque ela tinha muito ciúmes. Ela ficava o tempo todo... eu não podia ter amizade nem com irmãos, às vezes nem irmãs da igreja, do começo do casamento, até 3, 4 anos após... eu tinha amizade" (part. 03).

"Eu não brigava, ela que brigava comigo... ela que tinha ciúmes..." (part. 08).

Por seu turno, a infidelidade feminina representa uma questão de honra para o provedor, e muitas vezes é resolvida pelas vias de fato. O depoimento de uma das pessoas entrevistadas foi bastante claro neste sentido:

"Eu cheguei uma vez, há 14 anos, a fazer uma besteira com um cara. Ele começou a fazer propostas para ela, e eu acabei machucando, quase matando o rapaz" (part. 01).

Considerando todos estes resultados sob a perspectiva da vulnerabilidade feminina, podemos focalizar nossa discussão na desigualdade de gêneros, apontando elementos de exclusão envolvendo direitos, assimetria de poder, acesso limitado aos recursos sociais e, principalmente, os efeitos potencializadores da violência sexual, dependência econômica, coartação na tomada decisões e ausência de canais específicos para fazer prevalecer os direitos e necessidades das mulheres. Segundo Bastos e Szwarcwald (2000):

A combinação da violência material e simbólica da dupla moral faz com que para as mulheres seja mais difícil ter acesso a informações mais adequadas e atualizadas. Ademais ainda que estas sejam obtidas, é penosa a modificação de comportamentos, e mesmo que estes venham a ser alterados, a dificuldade instaura-se na manutenção de tais mudanças nas interações cotidianas... (p 70).

Tal anomia confina as mulheres em um mundo susceptível às violações dos direitos mais elementares (abuso sexual, impedimento à livre associação e expressão), potencializadas pela absoluta dependência para com o papel provedor masculino e subproletarização originada na lógica perversa da manutenção de um exército de reserva de força de trabalho desqualificado para o cumprimento de tarefas 
banais (mas fundamentais) para o andamento da carruagem social.

Alguns estudos sobre a infecção por HIV mostram aumento do número de mulheres contaminadas via relações heterossexuais, indicando a grande vulnerabilidade da mulher nas relações de gênero (Saldanha \& Figueiredo, 2004; Segatto, 1998). Essa vulnerabilidade se afirma na diversidade dos papéis sociais e sua determinação segundo gênero, organizando-se as relações com base na submissão da mulher. Discutindo as relações de gênero na América Latina, Parker (1997) afirma:

Por toda a região as relações de gênero se organizam em termos de arraigadas noções da "atividade" ou domínio da masculinidade, em contraste com a "passividade e submissão da feminilidade". A sexualidade masculina caracteriza-se como expansiva e quase incontrolável, enquanto a feminina é percebida como objeto do controle masculino. Espera-se que os machos iniciem sua atividade sexual assim que entrem na adolescência, e que tenham múltiplos parceiros sexuais, antes e depois de casados; das mulheres espera-se que se abstenham de atividade sexual antes do casamento, e que não tenham relações sexuais extraconjugais. Neste sistema machista, as mulheres exercem pouco ou nenhum direito em relação à expressão sexual dos homens, enquanto estes exercem um poder quase absoluto sobre o comportamento sexual das mulheres (p. 102).

As questões relacionadas aos papéis ativo e passivo no ato sexual são naturalizadas, mantendo a submissão da mulher nas relações de gênero e na divisão social do trabalho: tarefas domésticas, subemprego, desqualificação técnica, crenças a respeito de naturezas de gênero distintas (as mulheres enquanto continentes, fracas e submissas; os homens como insensíveis, fortes e dominadores). Mesmo havendo uma tendência à equalização da responsabilidade de prover a casa entre os parceiros, as mulheres geralmente se incumbem do trabalho doméstico, cabendo a elas o papel de cuidar das tarefas diárias do lar e da educação dos filhos, além de acudir o parceiro na doença e, muitas vezes, no momento da morte. Tais atividades são incorporadas à "essência do feminino" a tal ponto que, nos casos em que trabalha fora, à mulher são atribuídos os encargos de uma segunda jornada de trabalho. Sanchez (1994) afirma que, enquanto a mulher põe todos os seus ganhos a serviço da família, o homem guarda parte dos seus ganhos para sua diversão: “... o homem não somente tem o direito a uma moral sexual diferente, mas também a de guardar parte de seu salário..." (p. 15).

Outros autores, como Parker (1997) e Cabral (2003), salientam que as tentativas da mulher de equilibrar os papéis de gênero não são efetivas, dadas as condições de subordinação e anomia às quais as mulheres estão submetidas. De acordo com Bastos e Szwarcwald (2000),

... os gêneros, a despeito de inúmeras iniciativas, são tratados desigualmente em termos políticos, culturais,sócio-econômicos. Tais eixos de desigualdade apresentam dimensões macro e microssocial, ou seja, a observância ou não dos direitos, as relações assimétricas de poder e o acesso diferenciado a bens materiais e simbólicos. Desigualdades presentes em instâncias diversas se superpõem, gerando efeitos sinérgicos, como nos múltiplos riscos a que são submetidas mulheres de países em desenvolvimento, onde existe marcada desigualdade de gênero (p. 9).

A saúde é uma expressão das condições sociais, culturais e históricas em que o trabalho desempenha um papel crucial: o aumento crescente do trabalho feminino e a sobrecarga decorrente da dupla jornada podem levar à deterioração física e mental da mulher. Segundo Brito (2000),

Destaca-se também que as mulheres realizam grande quantidade de trabalho não pago, não só o chamado trabalho doméstico, mas também o trabalho de cuidar da família, que apresenta componentes emocionais importantes e que consomem muito tempo. Esse fato deve ser analisado pela sua importância na reprodução do quadro de pobreza e precariedade das mulheres (p. 11).

Com relação à sexualidade, alguns estudos (Birman, 1997; Saldanha \& Figueiredo, 2004) mostram que as gerações de casais que atualmente se contaminam por HIV têm uma história precária de informação sobre sexo, em que a percepção negativa das experiências sexuais, que são associadas com erro e sujeira, resulta em sentimentos de culpa e desconforto. Da mesma forma, estes pensamentos, junto com uma educação que tendia a incentivar comportamentos sexualmente mais ativos no homem, naturalizando o masculino, levaram a uma diferenciação no estabelecimento dos papéis de gênero na sexualidade. Segundo Pinel e Inglesi (1996), 
$\mathrm{Na}$ construção social da sexualidade masculina estabeleceu-se a expressão desta como sendo genital, ativa, promíscua e dissociada da afetividade. Da feminina, espera-se que seja extragenital, monogâmica, fiel, presa a uma fantasia romântica e submissa ao homem; diferenças tão marcantes entre os sexos só poderiam levar a um sistema desigual de poder, em que o do homem prevalece e é exercido sobre a mulher. Estas exigências sociais tornam ambos vulneráveis ao HIV (p. 65).

Saber o meio pelo qual o homem se contaminou por HIV é importante para a mulher, e quando o contágio provém de relações extraconjugais provoca na parceira uma revolta relacionada à quebra do comportamento ético conjugal. Segundo Segatto (1998),

...mesmo depois de terem sido vitimizadas por seus maridos, as mulheres ainda continuam sendo responsáveis pela manutenção da família, tendo que suportar preconceitos e ainda cuidar do parceiro, que na maior parte das vezes está em piores condições que ela. Para algumas a descoberta da contaminação ou da doença foi motivo para aproximação, da união do casal (p. 73).

O contágio por HIV/aids provoca ruptura no estado de saúde física e psicológica da pessoa, acarretando dificuldade de ajustamento social e despertando, principalmente no homem, sensação de grande impotência.

Outro aspecto importante é o uso do preservativo, que muitas vezes é visto como fator de controle reprodutivo, como colocam Vermelho et al. (1999):

... No começo, a camisinha era apenas um meio de evitar a gravidez. Quando questionadas mais detalhadamente sobre o motivo delas não gostarem deste método, respondiam "porque o parceiro não gostava". Além do mais, cabia ao homem decidir sobre sua utilização. O preservativo é ainda sinônimo de desconfiança no relacionamento e as poucas mulheres que desconfiavam estar sob risco relatavam desinformação ou completa impotência na negociação do uso do preservativo. O nível de comunicação sobre sexualidade e sua prática se resumem a papeis definidos socialmente e que devem ser aceitos sem questionamento... (p.15).

Os resultados obtidos neste estudo nos remetem à feminilização do contágio por HIV/aids, naturalizada na conjugalidade pelo processo de dominação do masculino sobre as relações de gênero. No processo de feminilização da epidemia, a transmissão heterossexual do HIV ocorre, na maioria das vezes, com mulheres entre 25 e 34 anos, atingindo o período mais fértil da vida adulta. Uma grande parcela destas mulheres se contaminou durante relações heterossexuais estáveis, geralmente com o marido ou o companheiro, o que foi determinado por elementos de vulnerabilidade ligados à visão masculina da conjugalidade, como o papel provedor masculino, a dialética do passivo-ativo e a naturalização da infidelidade masculina, categorias temáticas identificadas no presente trabalho.

Estes resultados permitem um enfoque na criação de elementos de resistência à subordinação de gênero no contexto da feminilização da aids, considerando-se autonomia e ganho em poder aquisitivo em relação ao provedor masculino e assertividade e processos de ativação/apropriação no enfrentamento do desequilíbrio na conjugalidade.

\section{REFERÊNCIAS}

Ayres, J. R. C. M., França Jr., I., \& Calazans, G. J. (1997). Aids, Vulnerabilidade e Prevenção. Em Associação Brasileira Interdisciplinar de Aids (Org.), II Seminário Saúde Reprodutiva em Tempos de Aids (pp. 20-37). Rio de Janeiro: IMS/UERJ.

Ayres, J. R. C. M. (2002). Educational practices and the prevention of HIV/aids: Lessons learned and current challenges. Interface. Comunicação, Saúde, Educação, 6(11), 11-24.

Bastos, F. I., Boschi-Pinto, C., Telles, P. R., \& Lima, E. (1993). O não-dito da Aids. The Hidden face of Aids in Brazil. Cadernos de Saúde Pública, 9(1), 90-96.

Bastos, F. I., \& Szwarcwald, C. L. (2000). Aids e pauperização: principais conceitos e evidências empíricas. Cadernos de Saúde Pública, 16(1), 65-76

Birman, J. (1997). A sexualidade entre o mal e as maledicências. Physis: Revista de Saúde Coletiva, 7(1), 7-13.

Bossa, A. C. M., \& Figueiredo, M. A. C. (2002). Grupo de acompanhamento da pediatria na Unidade Especial de Tratamento a Doenças Infecto-contagiosas. Revista do Serviço Social do Hospital das Clínicas da FMRP, USP, 2(2), 22-25.

Brito, J. C. (2000). Enfoque de gênero e relação saúde/trabalho no contexto de reestruturação produtiva e precarização do trabalho. Cadernos de Saúde Pública, 16(1), 195-204.

Cabral, C. S. (2003). Contracepção e gravidez na adolescência na perspectiva de jovens pais de uma comunidade favelada do Rio de Janeiro. Cadernos de Saúde Pública, 19(2), 283-292.

Castiel, L. D. (1966). Força e vontade: aspectos teóricometodológicos do risco em epidemiologia e prevenção do HIV/aids. Revista de Saúde Pública, 30(1), 100-109.

Clausson, N. I. (1989). Le Sida: La rèponse communautaire. Revue Cannadienne de Santé Publique, 80, 20-25. 
Farmer, P., Connors, M., \& Simmons, J. (1996). Women, poverty and Aids: An introduction. Culture, Medicine and Psychiatry, 17, 387-397.

Fernandes, A. M., Antonio, D. G., Bahamondes, L. G., \& Cupertino, C. V. (2000). Conhecimento, atitudes e práticas de mulheres brasileiras atendidas pela rede básica de saúde com relação às doenças de transmissão sexual. Cadernos de Saúde Pública, 16(1), 103-112.

Ferreira, R. C. M., \& Figueiredo, M. A. C. (2006). Re-inserção no mercado de trabalho. Barreiras e silêncio no enfrentamento da exclusão por pessoas com HIV/aids. Medicina, Ribeirão Preto, 39(4), 591-600.

Fioroni, L. N., Figueiredo, \& M. A. C. (2004). Female vulnerability to HIV seropositive among married women. Abstracts. In International Psychology Society (Org.), XXVIII International Congress of Psychology (pp. 1064-1075). Beijing: China.

Franco, F. G., \& Figueiredo, M. A. C. (2004). Aids, drogas e ser mulher. Relatos de mulheres soropositivas para o HIV. Medicina, Ribeirão Preto, 37(1), 106-116.

Heilborn, M. L. (1994). De que gênero estamos falando? Sexualidade, Gênero e Sociedade, 1, 1-8.

Herek, M. G., \& Glunt, E. K. (1988). An epidemic of stigma. Public reactions to Aids. American Psychologist, 43(1), 886-891.

Mota, M. P. (1998). Gênero e Sexualidade: fragmentos da identidade masculina nos tempos da Aids. Cadernos de Saúde Pública, 14(1), 87-99.

Parker, R. G. (1997). Reflexões sobre a sexualidade na Sociedade Latino-Americana: implicações para intervenções em face do HIV/aids. Physis: Revista de Saúde Coletiva, 7(1), 99-108.

Parker, R., \& Camargo Jr., K. R. (2000). Pobreza e HV/aids: aspectos antropológicos e sociológicos. Cadernos de Saúde Publica, 16(1), 89-102.

Pinel, A., \& Inglesi, E. (1996). O que é Aids. São Paulo: Brasiliense.
Ribeiro, D. F. (1996). A devolução do diagnóstico positivo do exame anti-HIV e o ponto de vista da pessoa infectada. Monografia Não-Publicada, Curso de Bacharelado em Psicologia, Faculdade de Filosofia, Ciências e Letras de Ribeirão Preto, Ribeirão Preto.

Saldanha, A. A. W. (1998). Aspectos psicossociais de prevenção da Aids em mulheres de baixa renda: entre o querer e o poder. Dissertação de Mestrado Não-Publicada, Pós Graduação em Psicologia Social, Universidade Federal da Paraíba, João Pessoa.

Saldanha, A. A. W., \& Figueiredo, M. A. C. (2003). Vulnerabilidade e construções do enfrentamento da soropositividade ao HIV por mulheres infectadas em relacionamento estável. Texto completo. Em Sociedade Lusófona (Org.), $4^{\circ}$ HIV/Aids Congress. A mulher e a infecção por HIV/Aids (pp. 49-57). Recuperado em 1 de Dezembro, 2003, de http://aidscongress.net

Sanchez, M. E. (1994). La mujer ante la crisis economica actual. Revista de Psicología Social Comunitária, 2(3), 9-16.

Scott, J. (1989). Gênero: uma categoria útil para a análise histórica. São Paulo: Columbia University.

Segatto, B. C. A. (1998). Até que a Aids nos separe: traídas pela confiança. Monografia não publicada, Curso de Graduação em Psicologia, Pontifícia Universidade Católica, São Paulo.

Schechter, M. T. (1993). Aids: The fictions, the facts. Canadian Medicine Association Journal, 148(5), 802-805.

Vaitsman, J. (1994). Flexíveis e Plurais: identidade, casamento e família em circunstâncias pós moderna. Rio de Janeiro: Rocco.

Vermelho, L. L., Barbosa, R. H. S., \& Nogueira, S. A. (1999). Women with Aids: Disclosing risk stories. Cadernos de Saúde Pública, 15(2), 369-379.

Recebido em 14/12/2006 Aceito em 27/06/2007

Endereço para correspondência : Marco Antonio de Castro Figueiredo. Avenida dos Bandeirantes 3900, Monte Alegre, CEP 14900901, Ribeirão Preto-SP E-mail: marcoacf@usp.br 